FULL RESEARCH ARTICLE

\title{
An innovative temporary escape ramp for deer and other wildlife
}

\author{
GINA E. MORIMOTO ${ }^{1 *}$, ANAE` B. OTTO $^{2}$, AND LAURA L. BURK- \\ HOLDER $^{1}$
}

${ }^{1}$ Pacific Gas and Electric Company, 3401 Crow Canyon Road, Room 150F, San Ramon, CA 94583, USA

${ }^{2}$ United States Forest Service, Sierra National Forest, Bass Lake Ranger District, 57003 Road 225, North Fork, CA 93643, USA

*Corresponding Author: gina.morimoto@pge.com

Concrete-lined water conveyance canals can be a significant source of mortality for ungulates and other wildlife, which can drown or become entrapped. Various types of wildlife escape structures have been deployed in canals with limited success. From 2011 to 2018, we used camera traps to monitor mule deer (Odocoileus hemionus) use of three different temporary wildlife escape structure designs with the goal of developing an effective escape structure for fawns. We monitored three to five locations at a hydroelectric water conveyance canal, operated by Pacific Gas and Electric Company in the foothills of Central California on the Sierra National Forest, in which trapped fawns had been detected previously during the maintenance period when the canal was dry. Mule deer activity and ramp use varied by year. During the monitoring period, deer were detected in the canal in all years except 2016 and 2017. Fawns and adults used the temporary escape structures to exit the canal in four of these years and $50 \%$ of mule deer detections showed ramp use overall. No deer were detected using the escape structures until jute netting and debris were added to the surface of the escape ramps in the third monitoring year. Prior to this modification, fawns were detected trapped in the canal investigating the ramps, but not using them to exit the canal. Deer may be more likely to utilize ramps covered with materials that mimic native ground cover. Seven other wildlife species were detected entering and exiting using the ramps with a general increase in use over years. Our temporary escape ramp design for small canals, when dry, appears to be novel and may be applicable in other areas. When compared to fencing or covering the canal, it is a relatively low-cost solution to reduce animal entrapment.

Key words: canal, drowning, entrapment, escape ramp, fawn, mule deer, Odocoileus hemionus, wildlife escape ramp 
In California, there are over $12,000 \mathrm{~km}$ of canals that transport water throughout the state for industrial, residential, and agricultural purposes. These types of open water conveyances can pose a threat to wildlife by fragmenting habitat, disrupting daily or seasonal movements, and can result in animal mortalities from drowning or entrapment (Rautenstrauch and Krausman 1989; Peris and Morales 2004). In some areas, concrete lined canals have been shown to be a significant source of wildlife mortality, particularly for ungulates (Latham and Verzuh 1971; Krausman et al. 1992). Mule deer (Odocoileus hemionus) are more likely to drown in concrete lined than in earthen canals (Bucci and Krausman 2015). One five-year study recorded 538 dead mammals in a 24.1-km concrete lined canal in northern Spain, 22\% of which were roe deer (Capreolus capreolus; Peris and Morales 2004).

In the foothills of central California, Pacific Gas and Electric Company (PG\&E) operates a hydroelectric facility with a network of canals that traverse portions of the Sierra National Forest. Mule deer fawns have become entrapped in the vertical-walled section of canals during the summer maintenance period when these water conveyance features are dry and not operating. In the Sierra Nevada, this time period coincides with the local neo-natal mule deer fawning period (Kroeker 2018).

Various types of wildlife escape structures have been deployed in canals with limited success (Nelson et al. 1978; Krausman et al. 1992). A combination of steps, ramps, and directional cables successfully allowed trapped mule deer to escape from a large concrete-lined canal with sloped sides in southwest Arizona (Rautenstrauch 1987). Few relevant solutions were found in the literature for the type and size of seasonally dry canal structures present in the study area. Stacked hay bales were successfully used as temporary escape ramps by deer and elk in a Washington state canal (Latham and Verzuh 1971; Nelson et al. 1978).

We tested stacked hay bales and escape ramps of our own design at five locations within a 2-km stretch of canal in which trapped fawns had been detected previously. We used camera traps to monitor attempted use and animal behavior around the escape structures, allowing us to adaptively modify structure design based on our observations during the study period. Our objectives were 1) to determine the effectiveness of our escape structures for mule deer and 2) to monitor which species of wildlife used the escape structures to exit the canal. Our study was focused on specific management objectives and is best described as applied research conducted to inform adaptive management of an observed issue.

\section{METHODS}

\section{Study Area}

We conducted our study along a canal that is owned and operated by PG\&E in North Fork, California (37.229, -119.510). The study area is in the central Sierra Nevada foothills with elevations ranging from 853.4 to $867.2 \mathrm{~m}$ (Fig. 1). The climate in the study area is characterized as Mediterranean, with cool wet winters and hot dry summers. Average monthly temperatures range from $0^{\circ} \mathrm{C}$ in January to $35^{\circ} \mathrm{C}$ in July and yearly precipitation averages $85 \mathrm{~cm}$. Snowfall is rare, averaging $5 \mathrm{~cm}$ annually. Dominant vegetation in the upper section of the canal consists of montane hardwood-conifer, primarily comprised of black oak (Quercus kelloggii), incense-cedar (Calocedrus decurrens), and ponderosa pine (Pinus ponderosa). The lower section of canal runs through blue oak woodland dominated by blue oak (Quercus douglasii), interior live oak (Quercus wislizenii), and California buck- 


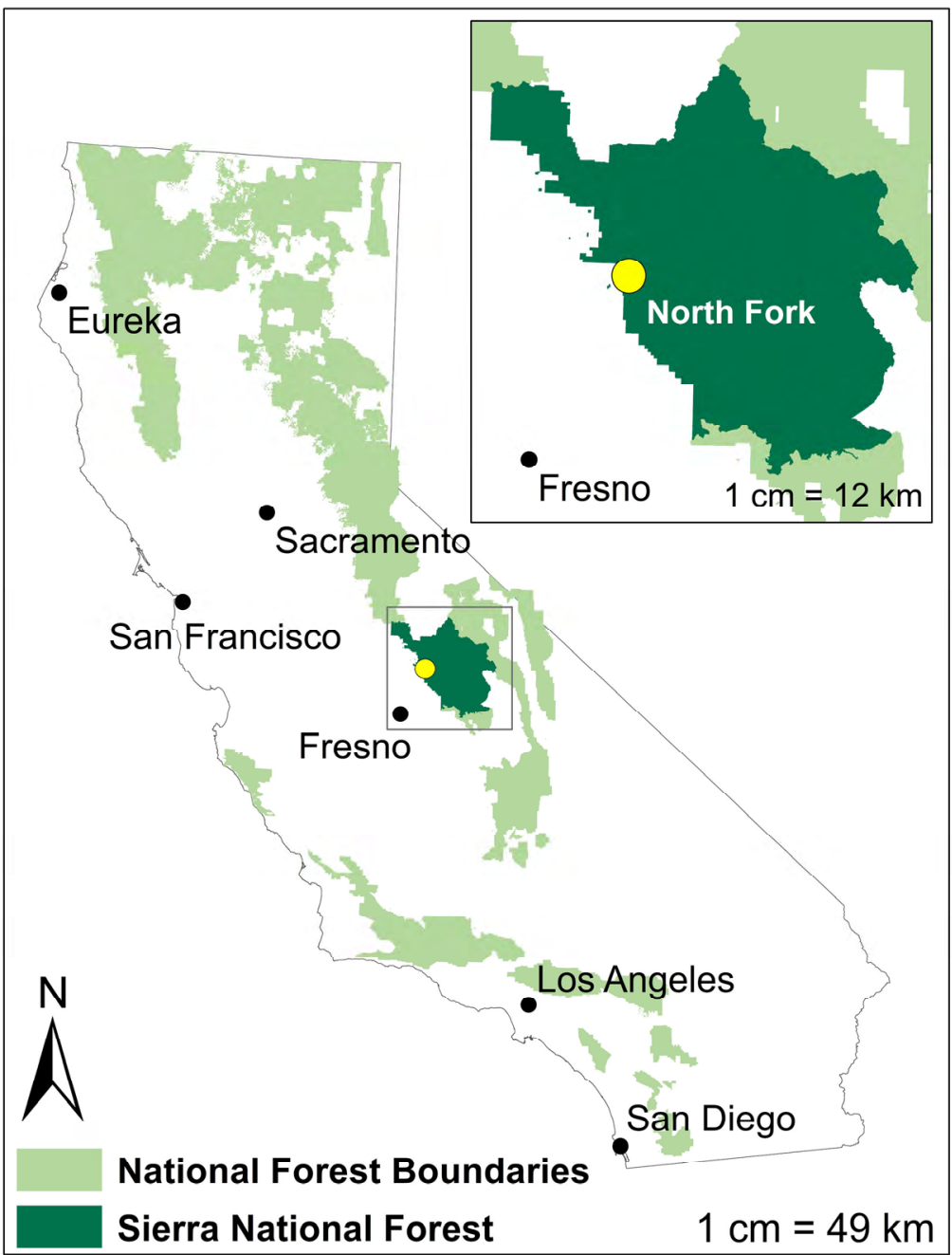

Figure 1. Study area located in North Fork, CA, USA.

eye (Aesculus californica), interspersed with annual grassland. Both resident and migratory mule deer use the study area.

The canal is part of the Crane Valley Hydroelectric Project (Federal Energy Regulatory Commission [FERC] Project Number 1354). The canal is $2.88 \mathrm{~km}$ long, with approximately $2 \mathrm{~km}$ of exposed canal that is mostly lined with concrete. We determined that the highest area of concern was the box flume portion of the canal due to the tendency for deer to try to jump over and subsequently fall in. The typical box flume canal dimensions are $1.83 \mathrm{~m}$ wide by $1.5 \mathrm{~m}$ tall, with vertical sides. There are nine crossings (bridges) suitable for deer along the $2 \mathrm{~km}$ portion of exposed canal. We began our study with five sites and gradually reduced the sites to three. These sites were selected based on areas where high deer activity was recorded in a Project-wide canal crossing study and where the public identified fawns falling into the canal. 


\section{Temporary Escape Ramp Design}

We required an escape ramp that met the following criteria: 1) easy to deploy and remove during/after the annual summer maintenance period; 2) would not affect the structural integrity of the canal; and, 3) economical (inexpensive to construct, deploy, and maintain). Initially in 2011, hay bales were stacked in a step configuration within the canal (Fig. 2). Four to six wheat hay bales were stacked at each site.

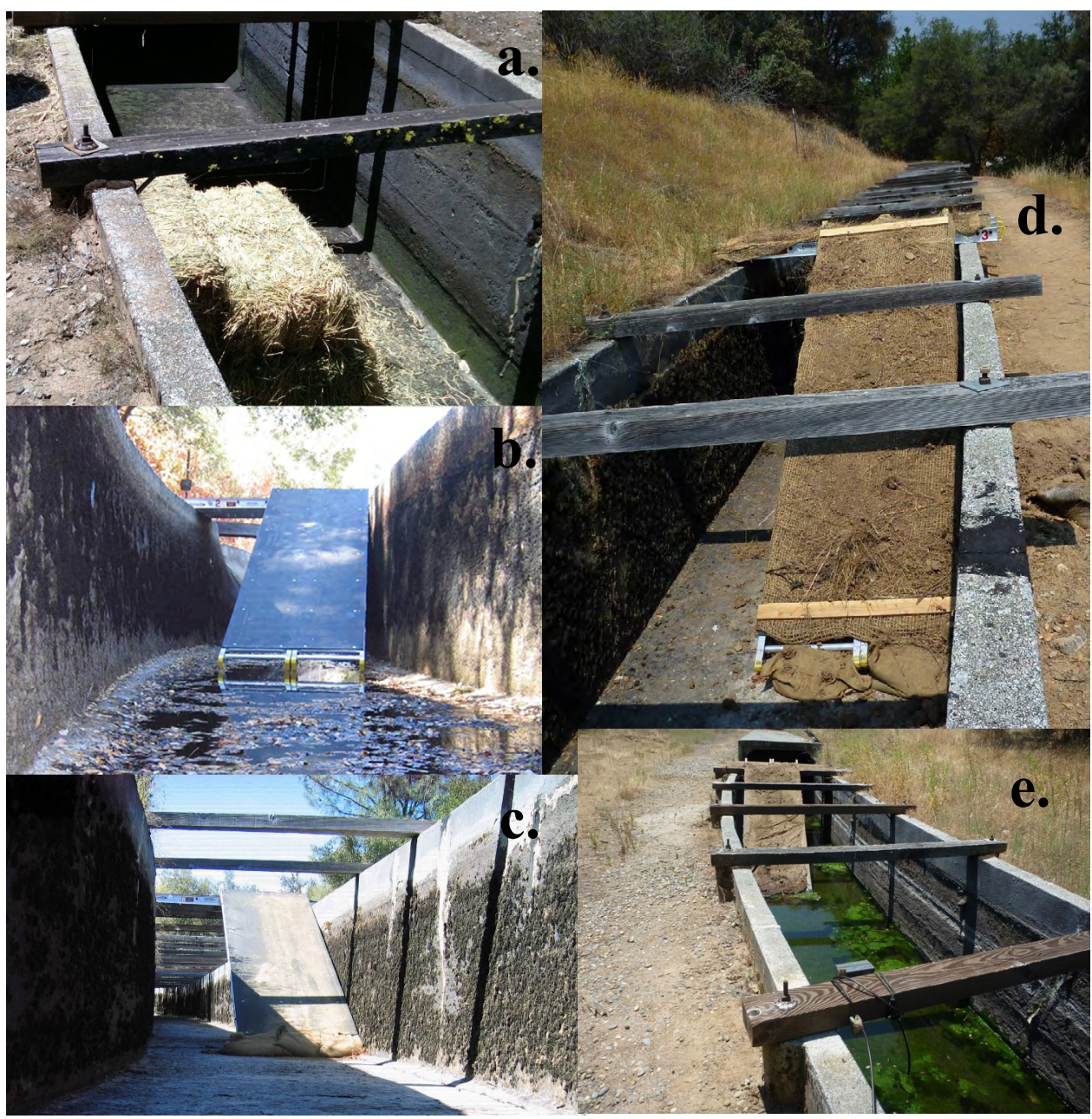

Figure 2. Different iterations of temporary escape structures used from 2011-2018 in canal located in North Fork, California: (a) Hay bales arranged in step configuration (2011), (b) Aluminum platforms covered with rubber sheets (2012), (c) Aluminum platforms covered with rubber sheets and sandbags installed at base of ramp (2012), (d) Aluminum platforms covered with rubber sheets, sandbags deployed at base of ramp, and jute netting and debris utilized (2013), (e) Aluminum platforms covered with rubber sheets, sandbags deployed at base of ramp, jute netting and debris utilized, and camera trap attached to canal crossbeam (2017). 
Due to the lack of successful results the previous year, in 2012 we used a different temporary escape structure designed specifically for the canal. The design consisted of aluminum stage platforms covered in neoprene rubber sheets that were $0.64 \mathrm{~cm}$ thick by $50.8 \mathrm{~cm}$ wide and secured to the canal with galvanized steel hardware to increase traction (Fig. 2; Appendix I). At each of the five sites, we used two $3.66 \mathrm{~m}$ by $0.56 \mathrm{~m}$ aluminum stage platforms that were placed side by side to serve as the ramp. At three sites that did not have existing bridges, we placed two $2.44 \mathrm{~m}$ by $0.56 \mathrm{~m}$ aluminum stage platforms side by side to create a bridge. The platforms were secured together with $0.95 \mathrm{~cm}$ steel bolts with washers. The ramps were secured to the bridges with $1.27 \mathrm{~cm}$-diameter U-bolts. The assembly was secured to the canal walls using steel bolts and locked to deter theft. At two sites, wood/iron supports were removed on top of the canal sides to install the ramps. The ramp angles ranged from $27^{\circ}$ to $32^{\circ}$. These angles were hypothesized to avoid attracting deer into the canal, while providing a means to exit the canal. From 2013-2018 we added jute netting and debris (i.e., dirt, plant material) on top of the rubber sheets to create a more natural appearance, and sandbags with native fill at the bottom of each ramp to eliminate any gaps that might be visible to wildlife (Fig. 2). Wooden slats were placed horizontally along sections of ramps in 2013 but were not attached in subsequent years. The entire ramp assembly was constructed with materials purchased from a local hardware store for under $\$ 1,000$ per site; this met our economical criterion.

\section{Camera Trap Models}

We used various camera traps during our study to monitor use of the temporary escape ramps as camera technology improved (Table 1). One camera trap was deployed per ramp site. The cameras were placed in metal security boxes with metal locks. Camera trap placement varied per site depending on the availability of stationary objects for camera installation. Each camera was secured to a stationary object such as a canal crossbeam inside the canal or t-post adjacent to the canal with Master Lock Python ${ }^{\mathrm{TM}}$ cable locks and bungee cords. The camera traps were generally placed with the entire ramp in the field of view to detect animals entering and exiting the canal. Trigger distances and camera angle/height placement were thoroughly tested during camera setup at each site to ensure the cameras would trigger if an animal used the temporary ramps.

Table 1. Camera trap models used during our study from 2011-2018 at canal in North Fork, California.

\begin{tabular}{llll}
\hline Camera Model $^{\mathrm{a}}$ & Year(s) Used & $\begin{array}{l}\text { Number of Photos } \\
\text { per Trigger }\end{array}$ & $\begin{array}{l}\text { Photo Delay Interval } \\
\text { (seconds) }\end{array}$ \\
\hline TrailMaster (35 mm film) & 2011 & 1 & 12 \\
PhotoHunter & 1 & 60 \\
Moultrie ${ }^{\circledR}$ Model M-880 & 2012 & 1 & 5 \\
Reconyx Hyperfire & $2013-2015$ & 4 & 0 \\
\hline
\end{tabular}

a Different camera models were used as technology improved. 


\section{Escape Ramp Deployment and Camera Trap Monitoring}

Escape ramp deployment was timed with annual canal maintenance. The annual maintenance period generally was a period of six weeks beginning in July and ending in August. The canal was mostly dry during this period. We initially deployed escape ramps at five sites from 2011 through 2012. We gradually scaled down the sites to three from 2014 through 2018 after determining lack of mule deer use at two sites (Table 2). A two to four-person crew installed the escape ramps after clearance was obtained to enter the dry canal. We installed the camera traps to coincide with the ramp deployment. We generally conducted weekly checks of the cameras and ramps throughout the monitoring period. During each camera check, we downloaded photos, checked the batteries, noted any sightings or relevant information at the site (e.g., vandalism), and adjusted the camera if necessary. At the end of the maintenance period, a two to four-person crew removed the ramps. We generally removed the cameras a week or two after the ramps were removed. We defined the monitoring period to coincide with installment and removal of the escape ramps (Table 2).

At the end of the monitoring period, we manually sorted through the photos and summarized the data by site, date, time, temperature, photo file name, species, behavior, and whether the target species, mule deer, used the escape ramps, as well as other wildlife that used the ramps. We also recorded other variables that may have affected deer activity in our study area, such as drought, wildfires, human activity, and water year type.

\section{Data Analysis}

We summarized camera monitoring data by tallying deer and other wildlife detections by site and year. We considered detections of the same species at the same site that were 30 minutes or more apart to be a single detection. Detections may include the same animals on multiple occasions. We chose 30 minutes between detections based on review

Table 2. Summary of escape ramp structure type, number of sites, and monitoring period when ramps were installed and removed throughout our study from 2011-2018 in North Fork, CA, USA.

\begin{tabular}{llll}
\hline Year & Escape Ramp Structure Type & $\begin{array}{l}\text { Number } \\
\text { of Sites }\end{array}$ & $\begin{array}{l}\text { Monitoring Period (Ramps } \\
\text { Installed/Removed) }\end{array}$ \\
\hline 2011 & Ramp Type 1 & 5 & 13 Jul 2011-8 Aug 2011 \\
2012 & Ramp Type 2 & 5 & 25 Jul 2012-22 Aug 2012 \\
2013 & Ramp Type 3, jute netting/debris installed on & 4 & 10 Jul 2013-15 Aug 2013 \\
& 19 Jul 2013 & & \\
2014 & Ramp Type 3 & 3 & 3 Jul 2014-7 Aug 2014 \\
2015 & Ramp Type 3 & 3 & 1 Jul 2015-6 Aug 2015 \\
2016 & Ramp Type 3 & 3 & 7 Jul 2016-11 Aug 2016 \\
2017 & Ramp Type 3 & 3 & 12 Jul 2017-16 Aug 2017 \\
2018 & Ramp Type 3 & 3 & 27 Jun 2018-20 Sep 2018 \\
\hline
\end{tabular}

${ }^{\text {a }}$ Ramp Type 1 = Hay bales; Ramp Type 2 = Aluminum platforms covered with rubber sheets; Ramp Type 3 = Aluminum platforms covered with rubber sheets, sandbags deployed at base of ramps, jute netting and debris utilized 
of the camera data to avoid double counting individuals that had not yet moved from the site during a detection and to achieve an index of activity in and around the canal over the monitoring periods. If more than one animal was visible in a single detection, each individual animal was counted. For deer detections we simplified age into two classes, first year fawns were classified as fawns and all other deer were considered adults. We noted photographs resulting from false triggers (e.g., wind or other non-wildlife trigger) or with inconclusive blurry images, but we did not include these photographs in results. Detections are shown as number of detections not standardized by the number of camera monitoring days. Due to the small number of detections, dividing by camera monitoring days resulted in small values with negligible to no differences in overall trend among years, compared to raw detection numbers. Our results are descriptive due to our overall small sample size. We pooled detections for all sites. We did not make comparisons between sites because the objective of the monitoring was to determine an effective temporary escape ramp for trapped fawns in the 2-km canal section, not to compare use among sites.

We detected mule deer in the camera field of view both inside and outside the canal and used all deer detections combined as an index of deer activity to compare to deer entrapment to indicate whether the camera monitoring was effectively recording ramp use.

\section{RESULTS}

The number of camera monitoring days and sites varied by year due to factors such as timing of the annual maintenance period, stolen or vandalized cameras or escape structures, and site selection based on previous use observations. Camera monitoring days included the total number of days that a camera was deployed and in working condition at each site with a temporary ramp installed.

We detected several wildlife species in and around the canal, including mule deer, striped skunk (Mephitis mephitis), raccoon (Procyon lotor), opossum (Didelphis virginiana), Merriam's chipmunk (Neotamias merriami), western gray squirrel (Sciurus griseus), California ground squirrel (Otospermophilus beecheyi), black-tailed jackrabbit (Lepus californicus), cottontail rabbit (Sylvilagus auduboni), dusky-footed woodrat (Neotoma fuscipes), black bear (Ursus americanus), mountain lion (Puma concolor), bobcat (Lynx rufus), gray fox (Urocyon cinereoargenteus), coyote (Canis latrans), California towhee (Melozone crissalis), black phoebe (Sayornis nigricans), and various other passerines, California quail (Callipepla californica), red-shouldered hawk (Buteo lineatus), Cooper's hawk (Accipiter cooperii), great horned owl (Bubo virginianus), and various bats.

We did not detect any animals using the stacked hay bales to exit the canal in 2011. Although fawns were detected in the canal in 2011 and 2012, they did not use the temporary escape structures to exit the canal (Fig. 3). We detected mule deer fawns and adults using temporary escape ramps to exit the canal in 2013, 2014, 2015, and 2018 (Figs. 3 and 4). We recorded the highest amount of ramp use in 2015 (62.5\% of deer detected in the canal used ramps), followed by 2013 (57.1\% of deer detected in the canal used ramps) and 2018 $(50.0 \%$ of deer detected in the canal used ramps; Fig. 3). There were no detections of deer in the canal using the temporary escape structures to exit until after the installation of jute netting and debris onto the surface of the ramps in 2013 (Fig. 5). No deer were recorded using the ramps to enter the canal throughout the monitoring period.

We detected mule deer fawns in the canal (regardless of ramp use) during the monitoring period in all years except 2016 and $2017(n=20)$, while mule deer adults were observed 


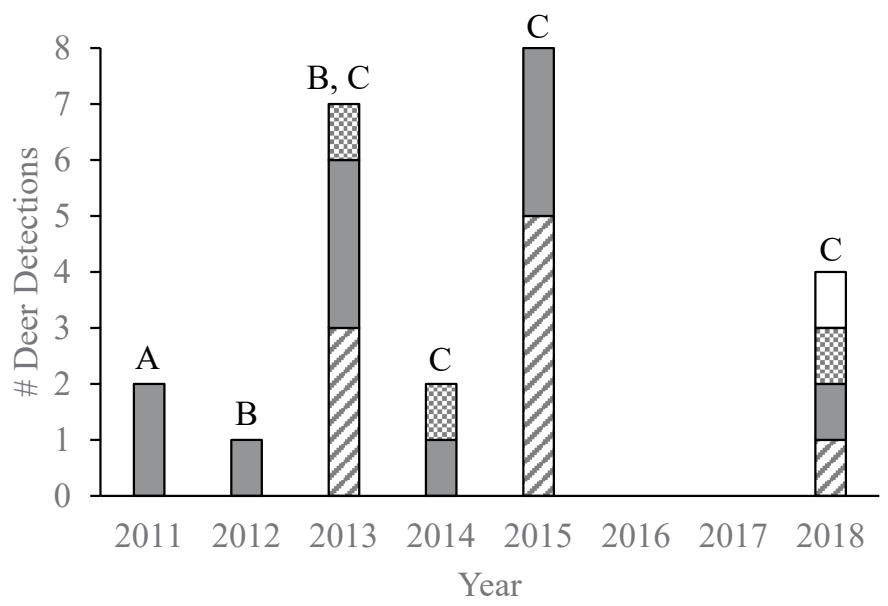

Figure 3. Number of deer detections inside canal located in North Fork, California for all sites from 2011-2018. Temporary escape structure designs: $\mathrm{A}=$ hay bales, $\mathrm{B}=$ aluminum, rubber covered ramps; $\mathrm{C}=$ aluminum, rubber, jute netting and debris covered ramps.

\author{
口Fawn Ramp Use $\square$ Fawn No Ramp Use \\ 圆 Adult Ramp Use $\square$ Adult No Ramp Use
}

Figure 4. Examples of mule deer utilizing the temporary escape ramps to exit the canal from 2014-2015 in canal located in North Fork, California: (a) and (b) pair of trapped fawns use ramp to exit canal as mother doe observes from above (2015), (c) mule deer using ramp to exit canal at night (2014).

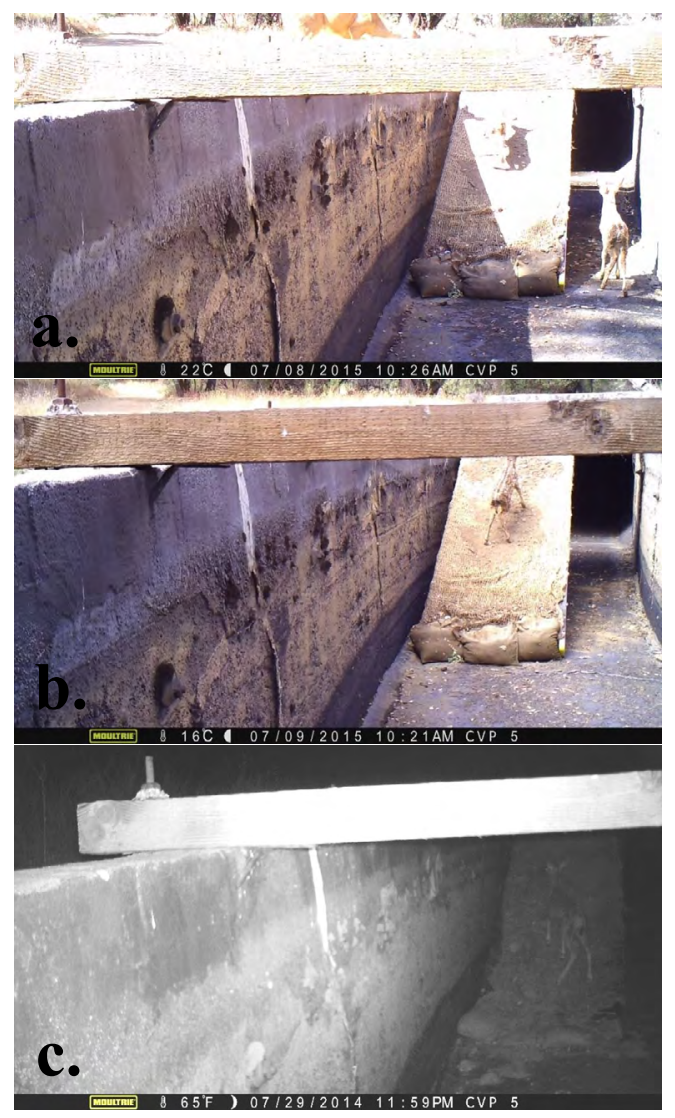




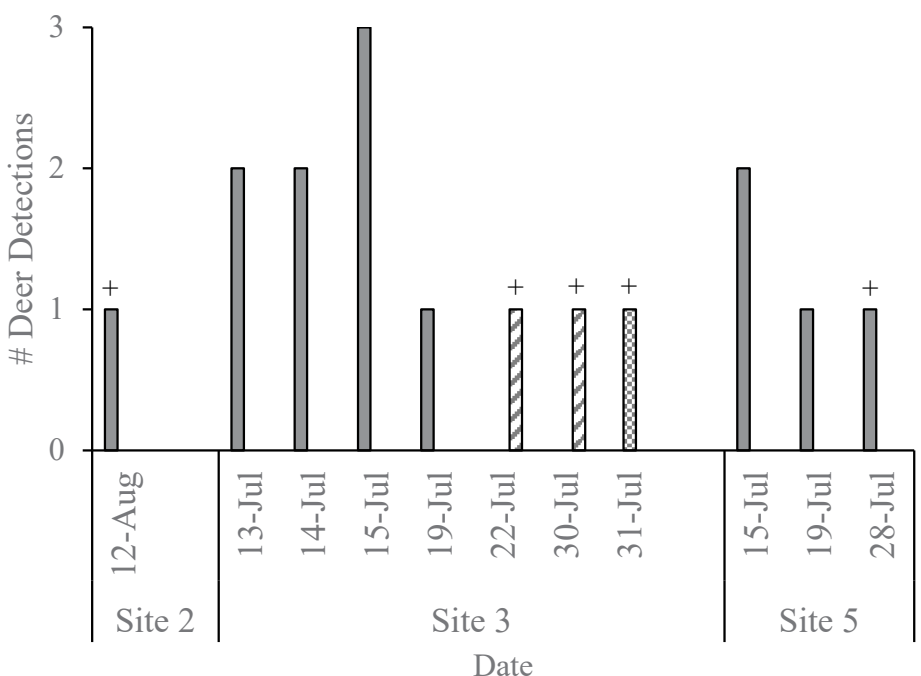

Date
Figure 5. Number of deer detections inside canal located in North Fork, California by site compared with timing of jute netting and debris installation onto temporary escape ramps in 2013. Plus sign $(+)$ indicates post installation of jute netting and debris.

\section{口No Ramp Use 圆Adult Ramp Use $\quad$ Fawn Ramp Use}

in 2013, 2014, and 2018 ( $n=4$; Fig. 3). Overall deer activity varied by year. We detected the highest levels of mule deer activity in and around the canal in 2013 and $2018(\mathrm{n}=47$ and 21, respectively), followed by moderate activity in 2011 and $2015(\mathrm{n}=12$ and 13, respectively; Fig. 6). We recorded the greatest number of deer detections in critically dry and below normal water years, but this pattern was not consistent among years (Fig. 6). We detected other wildlife using the ramps to enter or exit the canal from 2012 to 2018 (Table 3 and Fig. 7), with a general increase in use over monitoring years.

\section{DISCUSSION}

We began our study in 2011 using hay bales placed in the canal after a search of the published literature (Latham and Verzuh 1971) indicated successful use in other larger canals. The hay bales did not appear to be a viable solution when tested in the study area due to the difficulty in deploying and maintaining the structures throughout the maintenance period. After we failed to detect any use of the hay bales by mule deer or other wildlife, we sought the help of a PG\&E Engineer to design a temporary escape ramp. The new temporary ramp was deployed in 2012. While we did not record any photographic use of the new metal ramps, we observed small mammal tracks on one of the new ramps, indicating that it had used the ramp to exit the canal.

We had numerous problems with the film cameras used in 2012. For example, not capturing images of the small mammal that left tracks exiting the canal and a camera was stolen at one site. Therefore, we used digital cameras beginning in 2013 (Table 1), while keeping the same ramp design with some modifications (i.e., placing sandbags at the base of the ramps). 


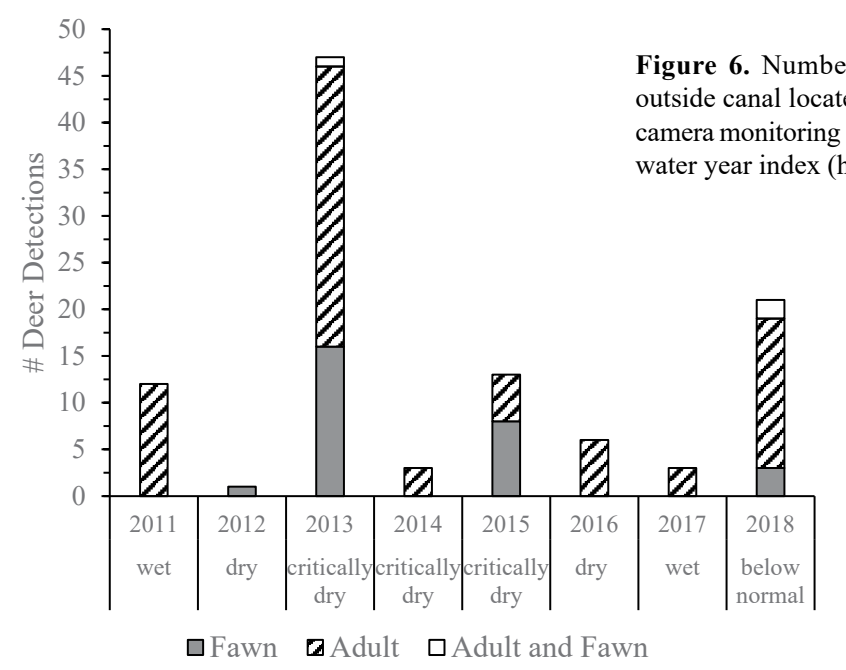

Table 3. Non-deer wildlife detected using temporary escape ramps in canal located in North Fork, CA, USA to enter and exit the canal from 2011-2018.

\begin{tabular}{|c|c|c|c|}
\hline Year & Species & Total Detections & Camera Monitoring Days \\
\hline 2011 & -- & 0 & 95 \\
\hline 2012 & Small mammal (tracks) & 1 & 117 \\
\hline \multirow[t]{2}{*}{2013} & Raccoon & 5 & 152 \\
\hline & Western gray squirrel & 2 & \\
\hline \multirow[t]{3}{*}{2014} & Raccoon & 3 & 108 \\
\hline & Bobcat & 1 & \\
\hline & Coyote $^{\mathrm{a}}$ & 3 & \\
\hline 2015 & Striped skunk & 2 & 111 \\
\hline \multirow[t]{3}{*}{2016} & Raccoon & 3 & 108 \\
\hline & Bobcat & 2 & \\
\hline & Striped skunk & 1 & \\
\hline \multirow[t]{2}{*}{2017} & Opossum & 1 & 108 \\
\hline & Raccoon & 7 & \\
\hline \multirow[t]{7}{*}{2018} & Opossum & 7 & 258 \\
\hline & Raccoon & 22 & \\
\hline & Bobcat $^{\mathrm{b}}$ & 5 & \\
\hline & Western gray squirrel & 3 & \\
\hline & Red-shouldered hawk & 1 & \\
\hline & Squirrel sp. & 1 & \\
\hline & Gray fox & 2 & \\
\hline
\end{tabular}

${ }^{\text {a }}$ One detection of coyote carrying dead fawn out of canal using ramp to exit.

${ }^{\mathrm{b}}$ One detection of two bobcat kittens using ramp to exit canal. 


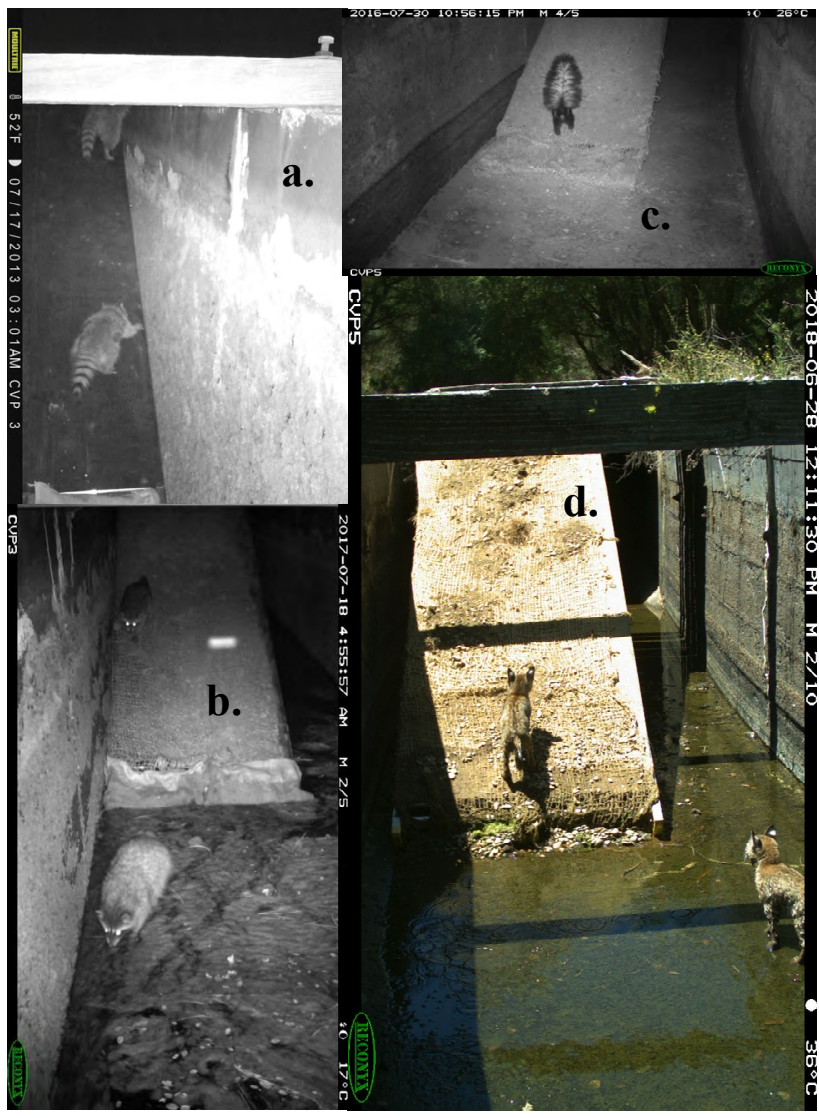

Figure 7. Examples of wildlife utilizing the temporary escape ramps to either enter or exit the canal from 2013-2018 in canal located in North Fork, California: (a) Raccoons using ramp to exit canal with no jute netting or debris installed (2013), (b) Raccoons using ramp to enter canal with jute netting and debris installed (2017), (c) Skunk using ramp to exit canal with jute netting and debris installed (2016), and (d) Bobcat kittens using ramp to exit canal with jute netting and debris installed (2018).

At the beginning of the 2013 camera monitoring period, we found a deceased fawn, two live fawns, and a cottontail rabbit that were trapped in the canal. One fawn and the cottontail rabbit were manually captured and released from the canal by U.S. Forest Service (USFS) staff, while the other fawn escaped the canal on its own. Upon reviewing the photos, we found that the fawns investigated the base of the ramps several times over three days but did not use the ramps. Rather than use the ramps, a fawn tried to jump out of the canal at the base of one ramp (Figs. 8a and 8b). After this discovery, we hypothesized that the fawns did not recognize the ramp as a means of escape due to the black surface of the ramps. We covered the surface of the ramps with jute netting and debris consisting of dirt and plant material on 19 July 2013. On 22 July 2013, we recorded our first successful use of the temporary escape ramps by mule deer fawns (Figs. 5 and 8c). Deer may be more amenable to using bridges and escape ramps covered with materials that mimic native ground cover (Peris and Morales 2004). That finding is similar to our observed change in ramp utilization after the jute netting and debris were added to the ramps. At the end of July 2015, the jute netting and debris were removed by an unknown person at the downstream-most site in our study area. Up until this point, trapped fawns successfully used the ramps with the jute netting and debris. Removal of the jute netting/debris covering coincided with the discovery of a trapped fawn that required manual capture and release by a PG\&E crew. 
Vol. 107, No. 3

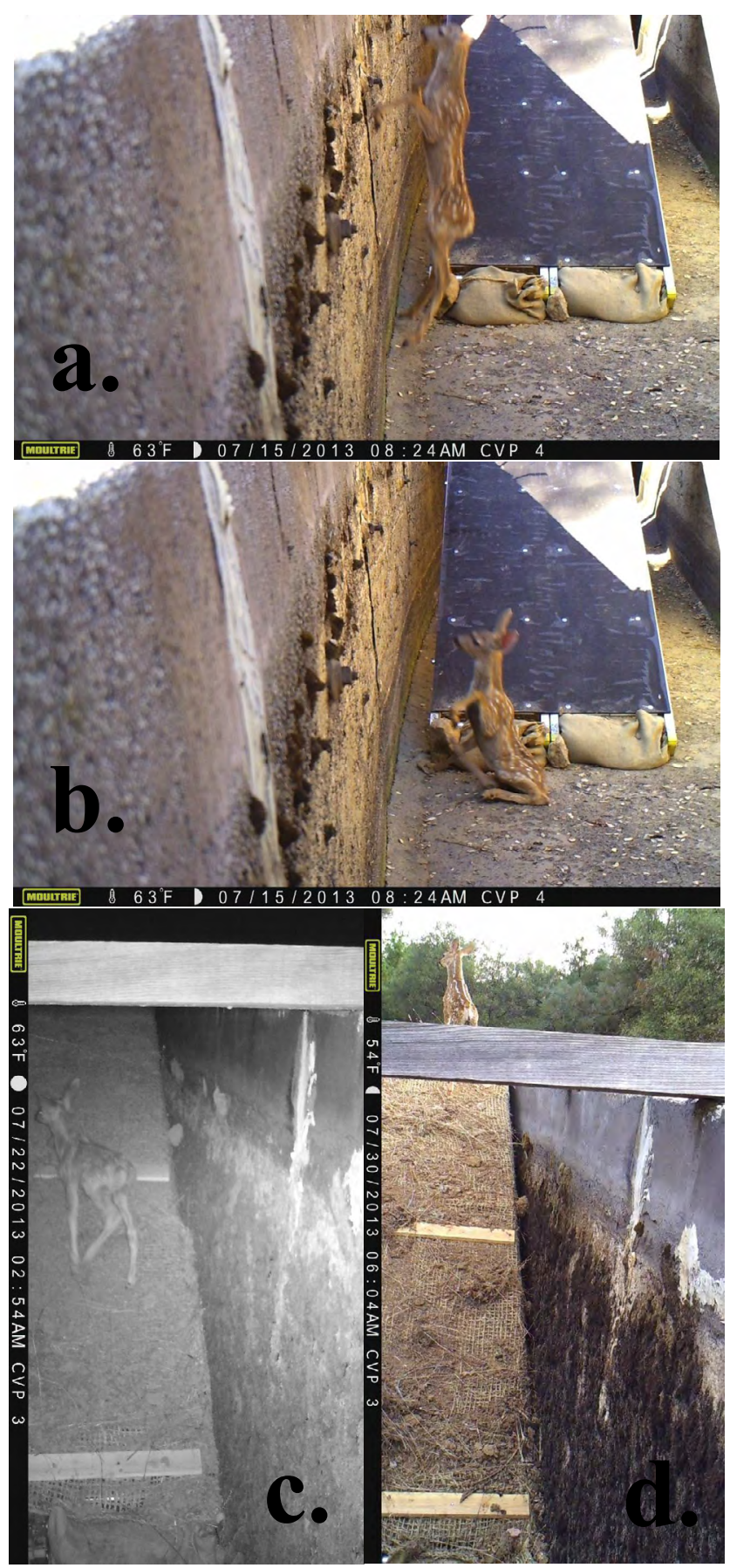

Figure 8. Example of adaptive modification of ramp design based on monitoring data at canal in North Fork, California: (a) and (b) Mule deer fawn attempts to jump vertically to exit canal while ignoring temporary escape ramp (15 July 2013). On 19 July 2013, jute netting and debris are added to the ramps. (c) and (d) mule deer fawns use ramp to exit canal on 22 July 2013 and 30 July 2013. 
The temporary escape ramps with jute netting and debris were not $100 \%$ successful in encouraging fawns to exit the dry canal. In August 2013 after jute netting was installed, a fawn was manually captured and released by a PG\&E crew. There was another instance of a trapped fawn manually captured and released by PG\&E and USFS in July 2018. Forty-five percent of all fawns detected in the canal used the ramps to exit (Fig. 3). Of the remaining $55 \%$ of fawns detected in the canal, some fawns were manually captured and removed, fawns may have escaped through other areas of the canal, or cameras may have failed to detect fawns escaping via the ramps. Three new wooden bridges were installed in the vicinity of our study sites in 2016, which may have contributed to the lack of deer detected in the canal in 2016 and 2017 during the monitoring period. In 2017, three deceased fawns were found in the canal prior to the ramp installment and monitoring period. No deceased deer were found in the canal in 2016. Human activity and the presence of domestic dogs could have affected the ability of mule deer fawns to use the ramps as well.

We documented more mule deer in the canal during years of higher deer activity (2013, 2015, and 2018) compared to other years (Fig. 3). We did not observe mule deer in the canal during the monitoring period in 2016 and 2017 which also coincided with low deer activity around the canal (Fig. 6). By using the mule deer activity in and around the canal as an index, we felt that we were able to effectively detect deer activity in the canal.

Drought conditions existed from 2012-2016 and 2018, and fires occurred near North Fork from 2013-2015 and 2017 (Table 4). These environmental conditions could have contributed to annual variability in overall deer activity. Water was present in the canal at least during some portion of the camera monitoring period in all years except 2014 and 2016. Mule deer and other wildlife may have been attracted to the canal due to the presence of water, particularly in 2015 (fourth year of drought). Kroeker (2018) noted that the environmental stressors of drought, wildfire, and insect infestation are acting as a catalyst for habitat change across the San Joaquin River watershed. Kroeker (2018) observed changes caused by wildfire that benefit deer including seral stage reset and rejuvenation of mature browse plants. All of these changes could have affected deer movements or habitat use patterns; however, the extent of these potential effects is unknown and require further study.

While the focus of our study was on mule deer use, we found that other wildlife also used the ramps. Raccoons used the ramps most often, followed by bobcats and opossums (Table 3). The steep angle of the ramps appeared to deter deer from entering the canal, but it still allowed other animals to enter and exit using the ramps. Raccoons, bobcats, and

Table 4. Environmental conditions during temporary escape ramp study in North Fork, CA, USA.

\begin{tabular}{lcl}
\hline Year & Drought Conditions? (Yes/No) & Fires Near Study Area (within 10 miles) \\
\hline 2011 & No & None \\
2012 & Yes & None \\
2013 & Yes & Gold Fire, Aspen Fire \\
2014 & Yes & Courtney Fire, Pines Fire, French Fire \\
2015 & Yes & Corrine Fire, Willow Fire \\
2016 & Yes & None \\
2017 & No & Railroad Fire, Mission Fire \\
2018 & Yes & None \\
\hline
\end{tabular}


opossums seemed to learn that they could enter and exit the canal over the years. In 2014, a coyote was observed carrying a dead fawn out of the canal.

While our temporary escape ramps allowed for at least $50 \%$ of mule deer to use the ramps, other modifications may improve the effectiveness. The angle of the ramps could be adjusted to a gentler slope. Caution should be taken so the angle is not so gentle that it provides a favorable point for fawns to enter the canal. Another potential modification is the use of wooden slats placed horizontally on the surface of the ramp to act as additional traction for mule deer fawns.

Over the course of our study, we were able to test the effectiveness of our new temporary escape ramps by adaptively making changes and conducting camera trap monitoring. We found that the escape ramps were used by wildlife species besides mule deer. Internet search engine results for "wildlife escape ramps" focus on small mammal/bird escape ramps from water troughs (Taylor and Tuttle 2007, USDA NRCS 2012) or deer jump outs related to highway fencing (Huijser et al. 2015). Designs are readily available for both types of structures. We developed a new temporary wildlife escape ramp designed to allow mule deer fawns to self-rescue from a dry vertical-walled canal. Our temporary escape ramp design for small canals appears to be novel and may be applicable in other areas. It is a relatively low-cost solution compared to fencing or covering the canal (Latham and Verzuh 1971).

\section{ACKNOWLEDGMENTS}

This study was a joint effort between PG\&E and USFS Sierra National Forest. PG\&E designed the ramps and paid for the materials and equipment. PG\&E supplied the digital camera traps. Monitoring was split between the USFS and PG\&E. We thank E. Doswald (PG\&E) for designing the escape ramps and the PG\&E Water Crew for installing and deploying ramps every year. T. Kroeker (California Department of Fish and Wildlife) was instrumental in providing advice and encouraged us to publish our work. S. Sutton-Mazzocco (USFS) took over monitoring in 2016, with assistance provided by T. Lowe (USFS). S. Johnson (PG\&E) and A. Henke (PG\&E) helped us monitor during the first year of this study. This study would not have been possible without the support of P. Merck (PG\&E), C. Ferguson (PG\&E), and J. Moore (PG\&E). We thank multiple reviewers whose comments and suggestions helped improve and clarify this manuscript.

\section{LITERATURE CITED}

Bucci, M. E., and P. R. Krausman. 2015. A fortuitous mitigation for desert mule deer along the All-American Canal. California Fish and Game 101:165-177.

Huijser, M. P., A. V. Kociolek, T. D. H. Allen, P. McGowen, P. C. Cramer, and M. Venner. 2015. Construction guidelines for wildlife fencing and associated escape and lateral access control measures. NCHRP Project 25-25, Task 84, National Cooperative Highway Research Program, Transportation Research Board of the National Academies, Washington D.C., USA.

Krausman, P. R., B. D. Leopold, K. R. Rautenstrauch, J. R. Morgart, and R. C. Etchberger. 1992. Desert mule deer mortality and the Central Arizona Project. Pages 43-47 in R.D. Brown, editor. The Biology of Deer. Springer, New York, NY, USA.

Kroeker, T. G. 2018. Upper San Joaquin watershed deer herd delineation, migratory behavior, and population dynamic telemetry project final report. California Department 
of Fish and Wildlife, Fresno, CA, USA.

Latham, H. S., and J. M. Verzuh. 1971. Reducing hazards to people and animals on reclamation canals. REC-ERC-71-36, Bureau of Reclamation, U.S. Department of the Interior, Denver, CO, USA.

Nelson, R. W., G. C. Horak, and J. E. Olson. 1978. Western reservoir and stream habitat improvements handbook. FWS/OBS-78/56, U.S. Department of the Interior, U.S. Fish and Wildlife Service, Biological Services Program.

Peris, S., and J. Morales. 2004. Use of passages across a canal by wild mammals and related mortality. European Journal of Wildlife Research 50:67-72.

Rautenstrauch, K. R. 1987. Ecology of mule deer in southwest Arizona. Dissertation, University of Arizona, Tucson, AZ, USA.

Rautenstrauch, K. R., and P. R. Krausman. 1989. Preventing mule deer drownings in the Mohawk Canal, Arizona. Wildlife Society Bulletin 17:280-286.

Taylor, D. A. R., and M. D. Tuttle. 2007. Water for Wildlife: A Handbook for Ranchers and Range Managers. Bat Conservation International, Austin, TX, USA.

USDA Natural Resources Conservation Service (USDA NRCS). 2012. Wildlife escape ramps for livestock watering troughs. Portland, OR, USA.

Submitted 29 October 2020

Accepted 8 January 2021

Associate Editor was S. Evans 


\section{APPENDIX I}

Temporary wildlife escape ramp engineering design for five original ramp locations in canal at North Fork, California.

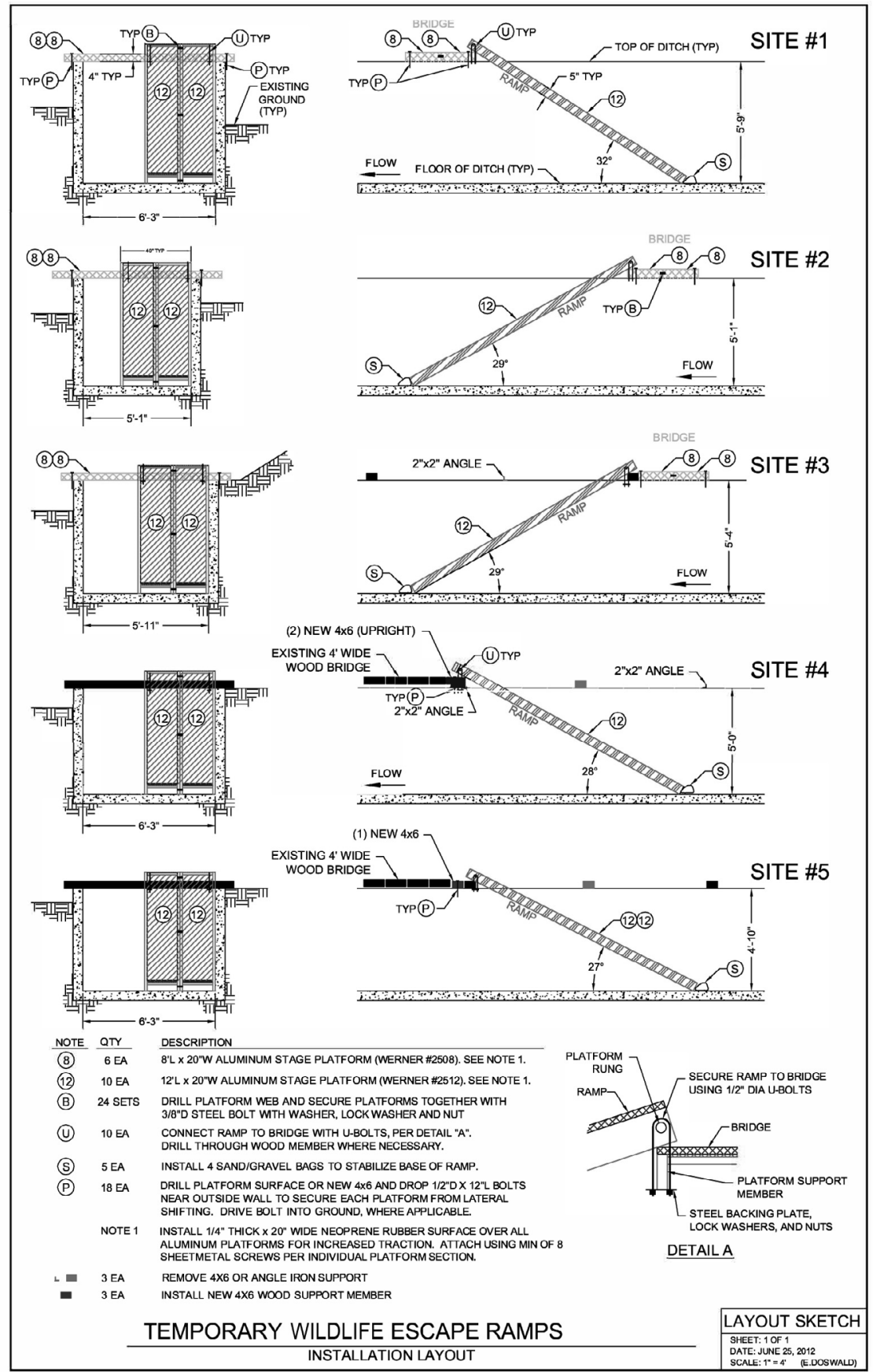

